\title{
Examining conservation attitudes, perspectives, and challenges in India
}

\section{Krithi K. Karanth*, Randall A. Kramer, Song S. Qian, Norman L. Christensen Jr.}

Nicholas School of Environment, Duke University, P.O. Box 90328, Durham, NC 27708, USA

\section{A R T I C L E I N F O}

Article history:

Received 29 February 2008

Received in revised form

24 June 2008

Accepted 30 June 2008

Available online 15 August 2008

Keywords:

Biodiversity

Conservation

India

Opinions

People

Social survey

Wildlife

\begin{abstract}
A B S T R A C T
Biodiversity conservation issues are often contentious and complex. Polarized debates on the effectiveness of protected areas and role of people inside them, charismatic species as conservation foci, and on specific policy initiatives are common among Indian and global conservationists. We surveyed Indian conservationists about the conservation effectiveness of protected areas and charismatic species, as well as status of conservation and research efforts. We expected differences among people based on professional affiliation, and educational background. We examined participants' opinions on conservation policies like Project Tiger and Elephant, the Forest Rights Act, and the Tiger Task Force Report. Participants ranked Indian research efforts as average, and identified a bias towards terrestrial species and ecosystems. Ninety-percent of participants considered reserves to be effective, many (61\%) participants felt that the situation of people living inside reserves is unsustainable, and many (76\%) felt the use of force to protect reserves from illegal human activities is acceptable. Classification and regression tree models for these questions suggested that non-academics were more likely than academics to agree with these positions. On the success of Project Tiger and Elephant, older participants were more likely to think these initiatives were a success. Many (63\%) participants felt the Forest Rights Act needed revision, particularly if they had doctoral degrees. Sixty-two percent of participants did not think Tiger Task Force was effective. Overall, participants' professional affiliation, age, and academic degree were important predictors of participants attitudes towards conservation initiatives.
\end{abstract}

(c) 2008 Elsevier Ltd. All rights reserved.

\section{Introduction}

Biodiversity conservation issues are often contentious and complex. Conservation debates and disagreements among Indian conservationists mirror those of their global counterparts. Indian conservationists are divided about rights of people living in reserves versus protection of wildlife, conservation-development initiatives in and around reserves, effectiveness of charismatic species as umbrella species, state versus local stakeholder control of reserves and natural resources, and specific conservation laws and policies
(Karanth and Madhusudan, 2002; MOEF, 2005; Madhusudan et al., 2006; Shahabuddin and Rangarajan, 2007; Karanth, 2007). Differing visions of how India's wild landscapes need to be managed are at the center of these debates (Saberwal and Rangarajan, 2003; Sivaramakrishnan, 2003; Karanth, 2003; Karanth and Bhargav, 2005; Rangarajan and Shahabuddin, 2006; Sekhsaria, 2007). These differences in opinion have polarized conservationists and hindered conservation efforts. Understanding the basis for these divergent views and differences of opinion is a vital first step to building consensus, addressing emerging challenges, and developing

\footnotetext{
* Corresponding author: Tel.: +1 919491 9338; fax: +1 3609372052.

E-mail address: krithi.karanth@duke.edu (K.K. Karanth).
}

0006-3207/\$ - see front matter (c) 2008 Elsevier Ltd. All rights reserved.

doi:10.1016/j.biocon.2008.06.027 
solutions that promote effective biodiversity conservation in India and elsewhere.

Attitude and opinion surveys are widely used to understand why people make decisions, and behave in certain ways. Surveys elicit respondents' beliefs about important issues that might influence their behavior and actions (that may or may not be directly observable). Attitudes play a major role in acceptance of environmental policies or management actions by the public, and conservationists in particular (Winter et al., 2005). Examining people's attitudes is important for formulating policies and management actions, and generating public awareness (Gillingham and Lee, 1999; Kaltenborn et al., 2006; Soto et al., 2001).

Individuals' worldview, familiarity with and knowledge of issues, and socio-economic characteristics affect their opinions and attitudes. Factors such as age, gender, education, and income level often influence people's support for particular issues (Kaczensky et al., 2004; Kleiven et al., 2004; Pratt et al., 2004; McFarlane et al., 2006). Other factors found to influence conservation attitudes include personal environment, value of open spaces, and experiential events (Kellert, 1991). Conservation surveys in particular, can help us understand attitudes and opinions towards conservation measures and policies. Examples include landowners' attitudes towards conservation schemes (Brook et al., 2003; Winter et al., 2005), public perceptions of biodiversity protection (Kramer et al., 2008), and community attitudes towards management regimes or particular species (Soto et al., 2001; Bandara and Tisdell, 2003; Caro et al., 2003; McFarlane et al., 2006).

\section{Background}

India is the world's second most populous country with a population growth rate of $1.3 \%$, and economic growth rate of $9.2 \%$. In the last 150 years, population density has quadrupled from 80 to 324 people/ $\mathrm{km}^{2}$ (Rangarajan, 2007). Despite rapid economic growth, there is widespread poverty $-35 \%$ of people live on less than $\$ 1$ a day, and $80 \%$ of people live on less than $\$ 2$ a day (UN, 2006). The majority (70\%) of people live in rural areas. India has been an agrarian country for much of its recorded history, and at present $46 \%$ of total land area is cultivated. In comparison, China has only $10 \%$ of land under agriculture (Rangarajan, 2007). Population growth coupled with rapid economic growth is exerting enormous pressure on India's limited natural resources. Like much of sub-Saharan Africa, South, and South-Eastern Asia, a huge proportion (57\%) of the country's labor force is dependent on agriculture (UN, 2006).

India has ten biogeographic realms, and is one of the world's 17-mega diversity countries that together support two-thirds of the world's biological resources (Rodgers and Panwar, 1988; Briggs, 2003). Among the flora, 33\% of the country's 49,219 plant species are endemic to India (MOEF, 1999). Although it covers just $2.4 \%$ of the world's area, India accounts for $7.3 \%$ of the world's terrestrial vertebrate species with 89,451 faunal species (MOEF, 2000). India has several charismatic species, including $40 \%$ of the world's tigers, and most of the world's Asian elephants. Both tigers and elephants are 'umbrella species', whose protection is thought to conserve other species and habitats. Current population estimates are 1500-3000 tigers and 10,000-20,000 elephants. Overall, conservative estimates suggest that $20 \%$ of Indian mammals face imminent extinction, and many have disappeared from over $90 \%$ of their historic range (Madhusudan and Mishra 2003).

The British left behind a mixed conservation legacy. From the 1850 s to 1920 s, they promoted widespread hunting of game animals, but they also set aside more than $600,000 \mathrm{~km}^{2}$ of government forests (Stebbing, 1923). With the expansion of agricultural frontiers, construction of the railways, and establishment of plantations, many species survived only in these areas. These hunting reserves and government forests laid the foundation for India's protected areas (Stebbing, 1923). The game preservation laws passed by the British standardized the hunting and shooting rules, but failed to curtail the disappearance of many species (Champion, 1934). Post independence, the first successful legislation to protect Indian wildlife was enacted in 1972 - the Wildlife Protection Act (MOEF, 2003). The impetus for this came from the personal commitment of Prime Minister Indira Gandhi, international pressure, and alarm raised by prominent conservationists (Rangarajan, 2001). This act banned hunting, and 'commercial' exploitation of timber and forest products from nature reserves in India.

The Indian government established many types of protected areas (national parks, sanctuaries) in the 1970s through 1990s. In 30 years, land under formal protection grew from less than $1 \%$ to greater than $4 \%$ of total area (Rangarajan, 2006). In 1980-81, the Indian government passed the Forest Conservation Act that prevented the diversion of Reserved Forest land for agriculture and development projects. Wildlife laws sought to protect forests, closed some areas to grazing, collection of forest products, and slowed down the legalization of forest occupation by homesteaders (Saberwal et al., 2001). Both laws facilitated the establishment and strict protection of several nature reserves (Karanth, 2003). In subsequent decades, conservation efforts have focused on managing the new challenges that have emerged in these reserves (Karanth and Madhusudan, 2002; Saberwal and Rangarajan, 2003; Karanth and Karanth, 2007; Shahabuddin and Rangarajan, 2007). During the 1980s and 1990s, de-centralization of power and failures of the federal and state government to address local challenges weakened conservation schemes.

Today, protected areas cover less than $5 \%$ of total land area in India, and they protect most of the country's remaining biodiversity. Indian reserves are under enormous pressure from people residing both inside and surrounding them. These reserves support many human activities (hunting, fishing, grazing, and collection of forest products) are widespread, (MOEF, 2000; Forest Survey of India, 2000; Das et al., 2006; Karanth et al., 2006). Human wildlife conflicts (crop raiding, livestock and human depredation) do occur, resulting in retaliation against some species (Karanth and Madhusudan, 2002). Fragmentation of habitats has added to wildlife threats. There is increasing concern that India will lose most of its rich fauna, and flora by the end of this century.

Project Tiger (launched in 1973) is one of India's most important conservation measures. This policy aimed to pro- 
tect this endangered cat, and provide federal funding and oversight to create tiger reserves in important habitats. The tiger became a flagship for new policies, and initiated widespread on-the-ground conservation initiatives (Rangarajan, 2001). The Indian government launched Project Elephant in 1992. This effort focused on protecting elephants, providing financial and technical support to Indian states, and conserving important elephant habitats and corridors. Both initiatives were developed by the Indian government to oversee protection of these species, and their habitats on countrywide scale. However, the resulting population estimates for each species and long-term effectiveness in conserving these species on-ground has come under intense criticism.

The Scheduled Tribes and Other Traditional Forest Dwellers Recognition Act, 2006 (from here on referred to as the Forest Rights Act) seeks to recognize and vest forest rights to forest dwelling people. Currently, Scheduled Tribes comprise $8 \%$ of India's population (Rangarajan, 2005). Many of the tribal members depend heavily on forests for their livelihood, and this has resulted in intense conflicts with wildlife in many reserves. The Tribal Act is an attempt to resolve these issues. This Act provides families access to and ownership of minor forest produce, grazing and cultivation rights, and access to traditional seasonal resources. The Act attempts to restore forest rights to these people on ancestral land, some of which consolidated under forest areas during the colonial and post independence periods (Kothari and Pathak, 2005; MOEF, 2005). It legalizes land occupied by each nuclear family (residing inside government forests prior to 2005, Rangarajan, 2005). The Indian Parliament passed the Act in 2006. India's Supreme Court is reviewing a case challenging the passage of this Act. Recently, there has been a decision to exclude tiger reserves from the jurisdiction of this Act (Ramnath, 2008).

Supporters of the Act argue that it will correct past injustices that some forest dwelling tribes were subjected to (Kothari, 2005; Prabhu, 2005). The Act has potential to provide secure land tenure, and livelihood security to many marginalized groups of Indian society (Sekhsaria, 2007; Ramnath, 2008). Critics of the Act believe that it will result in significant loss of forest cover (Jayakrishnan, 2005). A major provision of this Act is that it will override provisions of the Wildlife Protection Act (1972), the Forest Conservation Act (1980), and the National Forest Policy (1988), and dismantle many of country's current wildlife protection measures (Karanth and Bhargav, 2005; Madhusudan, 2005; Mohanty, 2005; Sahgal et al., 2005; Bhargav, 2007). Critics state it will be hard to separate deserving members from others who have no rights to these lands, and will reverse effectiveness of Indian conservation policies (Goenka, 2005; Karanth and Bhargav, 2005; Krishnaswamy, 2005; Mohanty, 2005; Ramnath, 2008). There is also concern that the Act will be used to front vested development initiatives such as mines and roads (Ramnath, 2008). For additional discussion on the Act see Bhargav, 2007; Krishnaswamy, 2005; Sekhsaria, 2007; and Ramnath, 2008.

In the last two decades, India has witnessed many wildlife crises. In 2005, tigers went locally extinct from Sariska Tiger Reserve. Sariska reserve had been cited as an example of a tiger reserve where there was successful local participation in the conservation of the tiger, and its habitat. In response to widespread public outcry, the Government of India instituted the Tiger Task Force Committee in 2005. This committee assessed the situation in Sariska, overall conservation problems in India, and developed strategies and guidelines to mitigate the situation.

Against this background of conservation history and policy in India, we examined attitudes and perspectives of modern day Indian conservationists on specific conservation issues and policies. We questioned participants on the quality of biodiversity research and dissemination of results, as well as perceived bias in conservation and research approaches (scale, species, and ecosystems). We focused on several questions. What are participants' attitudes toward conservation and research efforts in India? Are protected areas effective in conserving India's biodiversity? Should "force" be used to protect reserves? Can people live inside reserves? Do charismatic species like tigers and elephants serve as effective umbrella species? We examined their attitudes towards specific conservation initiatives like Project Tiger, Project Elephant, Forest Rights Act, and Tiger Task Force Report. We used classification and regression tree (CART) models to examine if participant characteristics such as age, education, role, affiliation, gender, and years of conservation experience may influence their attitudes.

\section{Methods}

\subsection{Survey methods and participants}

We conducted a sample survey to investigate the attitudes and perspectives of natural and social scientists, and conservation practitioners in India. We focused on urban and semiurban individuals in India who are actively involved in conservation. We pre-tested the survey with five conservationists in India to check for wording clarity, and revised the survey questions based on their recommendations. We utilized a "snowball-sampling" framework - starting with an initial list of 50 well-known conservationists. These participants recommended other individuals suitable to participate in the survey. We administered the survey questionnaire by postal, and electronic mail to 312 people from January to August 2006.

\subsection{Questionnaire design and analysis}

The questionnaire had 32 questions. Participants used a Likert scale to score their responses to indicate their level of agreement to particular questions. The Likert score scale ranged from 1 to 5 (with one representing strongly disagree to five representing strongly agree). We elicited narrative responses to a number of open-ended questions. A series of close-ended questions were used to obtain socioeconomic data. Participants provided details on their age, gender, academic degree, affiliation, role, and years of involvement in conservation. We grouped educational background into four categories: (bachelors, masters, doctoral, and other). Occupational groupings were academia, governmental, and non-governmental institutions, and independent. Participants classified themselves as natural scientists, social scientists (including conservation education and advocacy), conserva- 
tion managers, amateur naturalists, and other (law, media etc). Conservation experience was divided into four intervals: 1-10 years, $11-20$ years, $21-30$ years, and more than 30 years. Questions assessed participants' opinions on the quality of biodiversity research and dissemination of results, as well as perceived bias in conservation and research approaches (scale, species, and ecosystems).

We compiled questionnaire responses in Excel (Microsoft Office 2003), and analyzed the dataset in R (2.6) software. We used classification and regression tree (CART) models (implemented in package rpart) to assess the relationship between participant characteristics, and their attitudes towards conservation management and policies in India. Many disciplines such as ecology (Taverna et al., 2004), economics (Wezel and Potharst, 2007), medicine (Hess et al., 1999) use CART as an exploratory data analysis tool or as a model building method. CART recursively partitions data to yield models known as tree-based models (Brieman et al., 1984). CART models allowed us to explore and uncover structure in the data, screen variables, and capture non-additive behavior. Tree-based models are easier to interpret than linear models, and allow us to model interactions among predictors without pre-specifying them (Cirincione and Gurrieri, 1997). The resulting tree identifies a series of best predictors (depicted as nodes and branches) for the dependent variable. Qian and Anderson (1999) suggest that CART models can identify important factors that explain the variance in a response variable. We used CART to identify participant characteristics that might influence their responses to important conservation policies, and measures. In our case, CART allowed us to explore relationships with a small sample size, and identify the most important factors. We used classification models and assessed model performance by misclassification rate. The misclassification rate is the proportion of responses incorrectly classified by the fitted model. The rpart package in $\mathrm{R}$ reports this statistic using the percentage of improvement over the "root misclassification rate". This rate is the error based on a model in which every individual has the same probability of responding a particular way. For example, the model presented in Fig. 1 used a dataset with 167 participants, among whom 40 answered "no" and 127 answered "yes". Without using any predictor (i.e., all individuals exhibit the same probability of responding "yes"), the logical prediction of the answer from a future participant would be "yes". This prediction is correct $76 \%(127 / 167)$ of the time. The root misclassification rate is $24 \%$. The measure of a classification

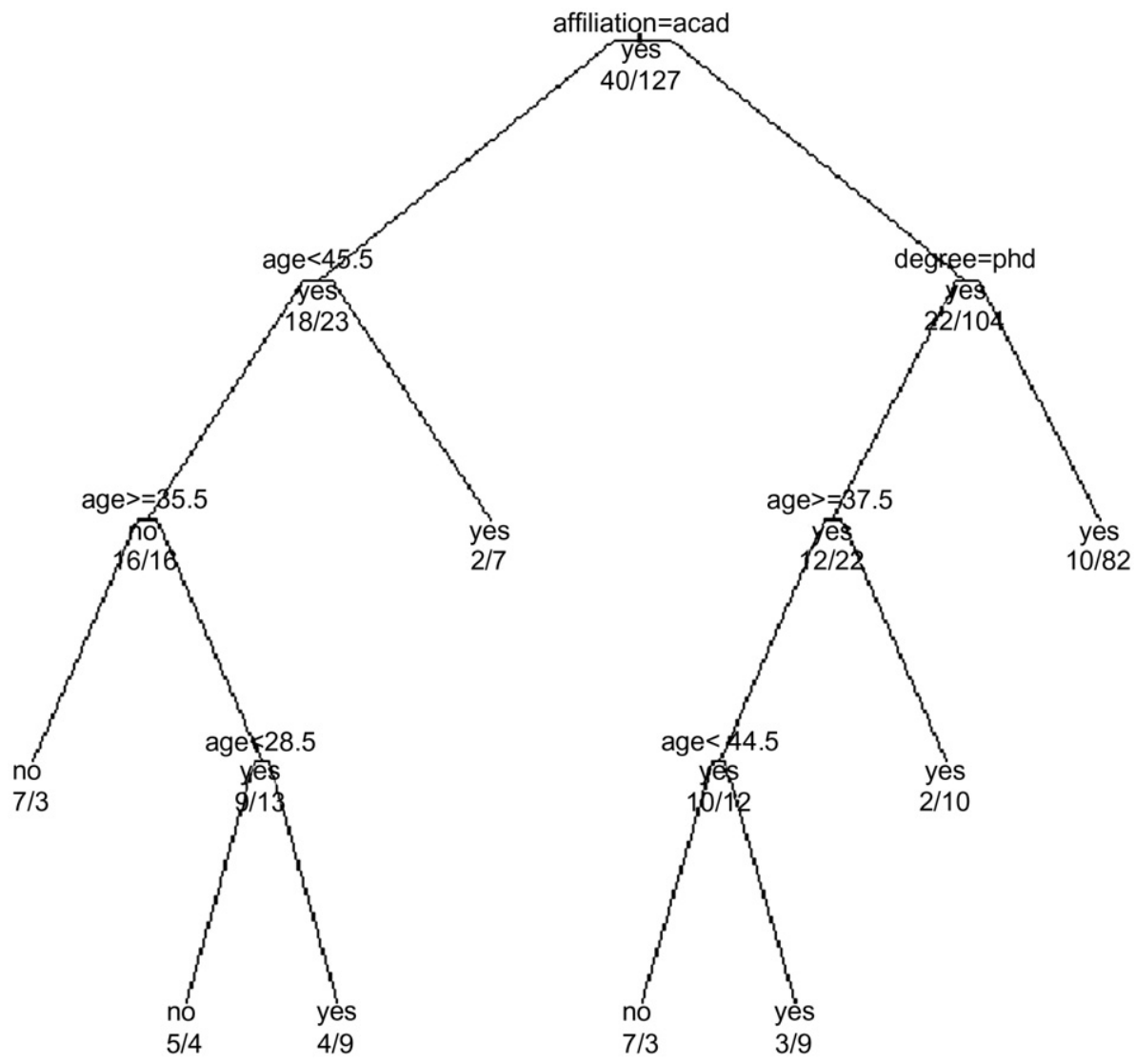

Fig. 1 - The classification tree model for the question on use of force in protected areas. The text above each split shows the variable that is split, and the condition for the left branch is stated. The original data set has 40 "no" responses and 127 "yes" responses. At the first node, academics (left branch) were equally likely to say "yes" or "no" and non-academics (right branch) overwhelmingly favor "no". Academics are likely to say "yes" (56\%) and non-academics are more likely to say "yes" (82\%). Among academics, older participants are more likely to say "yes". Among non-academics, those with doctoral degrees are more likely to say "yes". 
model "improvement" is the improvement over the root misclassification rate.

\section{Results and discussion}

\subsection{General characteristics}

We received 167 responses from the 312 individuals who were contacted, with a response rate of $54 \%$. Ninety-two percent of participants stated that they were actively involved in conservation. Details on survey respondents' gender, age, academic qualification, conservation experience, affiliation, and primary focus are in Table 1 . The typical participant was male, 40 years old, had a master's degree, worked for a non-governmental organization, and had an average of 11-20 years of experience. Participants worked in 28 of India's 30 States and Union Territories. Sixty-five percent of participants felt that some states were more effective in biodiversity conservation efforts. These states were Karnataka, Kerala, Maharashtra, Tamil Nadu, and Uttaranchal (four of these five states occur in southern India).

\subsection{Research and conservation focus in India}

Survey participants reported that they focused their research and conservation efforts in more than 15 different land coverhabitat types. The four most common habitats were deciduous forests (23\%), evergreen forests (18\%), scrub areas (12\%),

\section{Table 1 - Demographic characteristics of survey} participants

\begin{tabular}{|c|c|}
\hline Characteristics of participants & Percentage (\%) \\
\hline \multicolumn{2}{|l|}{ 1. Gender } \\
\hline Male & 83 \\
\hline Female & 17 \\
\hline 2. Average age & 39.9 years (range $23-79$ ) \\
\hline \multicolumn{2}{|l|}{ 3. Highest academic qualification } \\
\hline Bachelors & 21 \\
\hline Masters & 42 \\
\hline Doctoral & 34 \\
\hline Other & 3 \\
\hline \multicolumn{2}{|l|}{ 4. Conservation experience } \\
\hline 1-10 years & 41 \\
\hline $11-20$ years & 33 \\
\hline 21-30 years & 17 \\
\hline$>31$ years & 9 \\
\hline \multicolumn{2}{|l|}{ 5. Affiliation } \\
\hline Government & 19 \\
\hline Non-governmental organization & 52 \\
\hline Academic institution & 25 \\
\hline Independent & 4 \\
\hline \multicolumn{2}{|l|}{ 6. Primary focus } \\
\hline Natural science & 40 \\
\hline Social science, policy and education & 16 \\
\hline $\begin{array}{l}\text { Conservation management and } \\
\text { advocacy }\end{array}$ & 19 \\
\hline Amateur naturalist & 9 \\
\hline Other & 16 \\
\hline
\end{tabular}

and grasslands (11\%). Research and conservation efforts were conducted at different scales, with local (park level) being the most common (33\%). The majority of participants $(68 \%)$ worked solely on terrestrial species, while some (5\%) worked solely on aquatic species, and the rest (27\%) worked on both. Participants worked with more than nine major taxonomic groups, and 78 individual species of animals and plants. The most common groups were mammals (34\%), birds (21\%), and flora (19\%). Fifty-three percent of participants felt that there was a taxonomic bias in species studied by researchers. The three most commonly listed species were tigers, elephants, and leopards. Many participants felt that terrestrial species (3.7/5.0 Likert score), and terrestrial ecosystems (3.7/5.0 Likert score) were given too much emphasis. Concurrently, they also felt that aquatic species (3.5/5.0 Likert score), and aquatic ecosystems (3.6/5.0 Likert score) were given too little emphasis.

Participants felt that the quality of biodiversity research in India was average relative to global standards (2.8/5.0 Likert score). The two major reasons chosen by participants for constraints in reaching global standards of research were generally poor state of science education in the country $(37 \%)$, and insufficient allocation of funds to science education and research (33\%). Participants suggested many reasons why Indian researchers lagged behind their international counterparts. Many stated that they had conflicts with the forest and wildlife departments. Conflicts arose from participants not being allowed to conduct research inside reserves (denied permits, or given permits that did not accommodate their sampling framework). This was corroborated in a recent paper by Madhusudan et al. (2006). Some felt that the bureaucracy, and corruption in the system were too pervasive to overcome. Participants also stated that there were very limited educational opportunities in ecology and conservation in India. They felt that there are relatively few research institutions with mediocre faculty, and no financial support to pursue research. Some observed that educational opportunities were often restricted to English speakers, and there was no support or educational material in the regional languages. The lack of co-operation, and communication between governments and non-governmental organizations, as well as limited funding from Indian granting agencies were also suggested as reasons for mediocre research.

The majority of participants (81\%) stated that they obtained scientific information from both primary and secondary sources. Participants expressed their views, and disseminated their results through many outlets (radio stations, television channels, magazines, and newsletters). Participants published their results in 49 scientific journals. There was wide consensus that research results were disseminated poorly, and rarely accessible to the public and policy makers. Participants suggested that there is a general disinterest in conservation issues among the public, government, business, and political entities. Participants highlighted that researchers collaborated with international media and audiences to further their personal profile, but did not engage policy makers and local communities once results were available. Many participants suggested that this might be improved by increasing the number of popular articles written, wider use of the internet, and opening forums for public debates. 
Table 2 - Summary of tree models

$\begin{array}{llcc}\text { Question } & \text { Factor } & \text { Discussion } & \text { Model } \\ & & \text { improvement }\end{array}$

\begin{tabular}{ll}
\hline $\begin{array}{l}\text { Should force be } \\
\text { used in protected }\end{array}$ & Primary: affiliation \\
areas & Secondary: age, degree
\end{tabular}

Can people live inside protected areas

Can participatory approaches work

Primary: affiliation Secondary: age, degree

Project Tiger

Project Elephant

Forest Rights Act

Tiger task force report
Primary: age Secondary: role, age

Primary: age Secondary: affiliation, age

Primary: degree Secondary: conservation, involvement, age

Primary: conservation, involvement Secondary: degree, age
Among all participants, 76\% said "yes". Affiliation is the primary predictor of this response. Academics are likely to say "yes" (56\%), but this is much less than the response of the overall population. Nonacademics are more likely to say "yes" (82\%), which is higher than of the overall population. Among academics, older participants (77\%) are more likely to say "yes". Among non-academics, those with doctoral degrees are more likely to say "yes" (82\%), and those older than 37.5 years are more likely to say "yes" (65\%). See Fig. 1

Among all participants, 62\% said "no", 31\% said "under certain conditions", and 7\% said "yes". Affiliation is the primary predictor with academics responding differently. Among academics, 30\% said "no", 61\% said "under certain conditions", and 9\% said "yes". Among non-academics, $72 \%$ said "no", 21\% said "under certain conditions", and $7 \%$ said "yes". More people said "no" if they were non-academics. No other characteristics emerged significant

Among all participants, 44\% said "yes", 38\% said "under certain conditions", and $18 \%$ said "no". Affiliation is the primary predictor. Among academics and NGOs, 39\% said "yes", 44\% said "under certain conditions", and $17 \%$ said "no". This group had very similar responses from the overall population. Among people employed by government and other places, $40 \%$ said "yes", 23\% said "under certain conditions", and $20 \%$ said "no". This group was more different from the overall population

Among all participants, $60 \%$ said "yes". Age is the primary predictor of this response. Younger people (<33.5 years) are more likely to say "no" $(53 \%)$ and older people are more likely to say "yes" (66\%). Younger people have dissimilar responses, and older people have similar responses to the overall population. Among older people, those who work in academia and NGOs are more likely to say "yes" (61\%), and this is similar to the overall population. See Fig. 2

Among all participants, 51\% said "yes". Age is the primary predictor of this response. Younger participants ( $<43.5$ years) more likely to say "no" (54\%), and older people (>43.5 years) are more likely to say "yes" (60\%). The percentage of people saying "yes" was higher among older people. People between 26 and 43 years of age are more likely to say "no" (57\%). Older people who do not work in government, NGOs, or academia are more likely to say "yes" (61\%)

Among all participants, $63 \%$ stated that act needs to be "changed", $35 \%$ stated that it should "not be enacted", and only $2 \%$ stated it "should be enacted" in its current form. Degree was the primary predictor of this response. Among participants with doctoral degrees, $75 \%$ that the Act needs to be "changed", 18\% felt that it should "not be enacted", and $7 \%$ stated it "should be enacted" in its current form. This group has a higher percentage of people wanting the act to be changed. Among participants without doctoral degrees, 57\% stated that the Act should "change", 43\% felt that it should "not be enacted". This group has a lower percentage of people wanting the act to be changed, but "no" one who thinks the Act is acceptable in its current form. Overall, very few participants felt that the Act was acceptable in its current form

Among all participants, 38\% thought it was a "step forward", 27\% were "unfamiliar" with it, 20\% thought it was "no different", and $16 \%$ thought it was a "step backward" from previous reports. Conservation involvement was the primary factor. Among people involved in conservation, $40 \%$ thought it was a "step forward", $23 \%$ were "unfamiliar" with it, $20 \%$ thought it was "no different", and $17 \%$ thought it was a "step backward". The proportions did not change much between all participants compared to those involved in conservation

\subsection{4}




\subsection{Protected areas, people, and conservation threats}

Many participants agreed that India's current protected areas are effective (3.4/5.0 Likert score) in conserving biodiversity. The majority of participants $(90 \%)$ stated that the proportion of land under protected area status in India is insufficient to conserve biodiversity, and that the proportion needed to increase. The suggested increase ranged from $6 \%$ to $50 \%$ of total land area (average was $15 \%$ and median was $10 \%)$. There were more than 15 types of conservation threats categorized for India. The six most serious threats identified by participants were habitat fragmentation, human-wildlife conflicts, deforestation, land conversion, mining, and hunting of wildlife. Suggestions for improving conservation efforts involved a variety of approaches. Some participants (34\%) felt that this required changes in forest and wildlife management expertise, infrastructure, and better accountability. Others (24\%) felt that it was important to involve local communities in sharing benefits from reserves. Other suggestions included partial removal of people from nature reserves (16\%), and complete removal of people from reserves (11\%).

The use of "force" to protect reserves from illegal human activities was acceptable to many participants (76\%). Participants' suggested several enforcing agencies: forest and wildlife personnel, setting up a new specialized park protection force, local police and law enforcement agencies, non-governmental organizations, and guards from the army. Tree-based modeling allowed us to examine the effects of participant characteristics (age, gender, degree, affiliation, role, conservation involvement, and years of experience) on their "yes" or "no" response to this question about the use of force. The resulting tree (Fig. 1) suggests that affiliation is the primary factor, with age and degree as the secondary factors. Both academics and non-academics are likely to approve of the use of force to protect reserves, but the percentage is much higher for non-academics (Table 2).

We asked participants if people could sustainably live inside protected areas in the long term. Most participants (61\%) did not agree, although some (32\%) felt this could be sustainable if appropriate guidelines were established. A second tree model identified affiliation as the primary factor affecting views towards people living inside reserves. Participants who worked for the government, NGOs, and others generally felt this was not feasible, whereas academics were supportive of people living inside reserves (Table 2). Participants distinguished fully protected zones and extractive zones in reserves. The majority (63\%) felt that both types of zones were important, although some (35\%) felt that fully protected zones were more important. Representative comments of participants on the effectiveness, and importance of protected areas are summarized in Table 3.

We asked participants whether they believed participatory conservation approaches could work. Many (> 84\%) participants were familiar with participatory approaches to conservation. Among all participants, 44\% said "yes" (participatory approaches could work), 38\% said under "certain conditions", and $18 \%$ said "no". The tree model identified affiliation as the primary factor influencing these responses. Respondents affiliated with NGOs and academic institutions were more likely to support participatory approaches (Table 2). The most common observations and comments of participants on the use of participatory approaches in conservation are in Table 3.

\section{Table 3 - Summary of participants comments on reserves in India}

People

- Relocate people from important reserves, especially in places where people want to relocate outside, and provide them with suitable alternatives (13)

- Promote conservation education programs, and create awareness among local communities that live in/around reserves (10)

- Communities that have historic-cultural ties to the reserves should be allowed access to them(6)

- Provide alternative livelihood options, and make people less dependent on reserves (4)

- Lifestyles and standards of living of forest dwellers have changed, and are incompatible with wildlife conservation (3)

- Develop secure property rights institutions, and link conservation benefits to local livelihoods (3)

Management and research

- Strict enforcement of laws, and protection by the wildlife and forestry departments (12)

- Set aside core and inviolate areas, and prevent human access, but allow access in buffer areas (5)

- Requires strong support of the government (3)

- Increase collaboration with NGOs, and involve them in decision making (3)

- Integrate unprotected areas rich in biodiversity using creative solutions (3)

- Involve communities in benefit sharing (ecotourism etc.), and involve them in protection (2)

- Promote research, establish wildlife monitoring programs, and adapt management decisions accordingly (2)

Participatory approaches

- The need for involvement must come from within the local communities, and they must derive benefits (17)

- Rights and responsibilities must be outlined at the outset, and regulatory mechanisms within the community must be n place (10)

- Works if resource use patterns, and conservation priorities do not seriously compromise each other (8)

- Need regulatory agencies, and must involve local NGOs. Local organizations and individuals with long-term commitments to the area are most effective, and can engage local communities (5)

Note: Numbers in brackets refer to number of survey participants. 


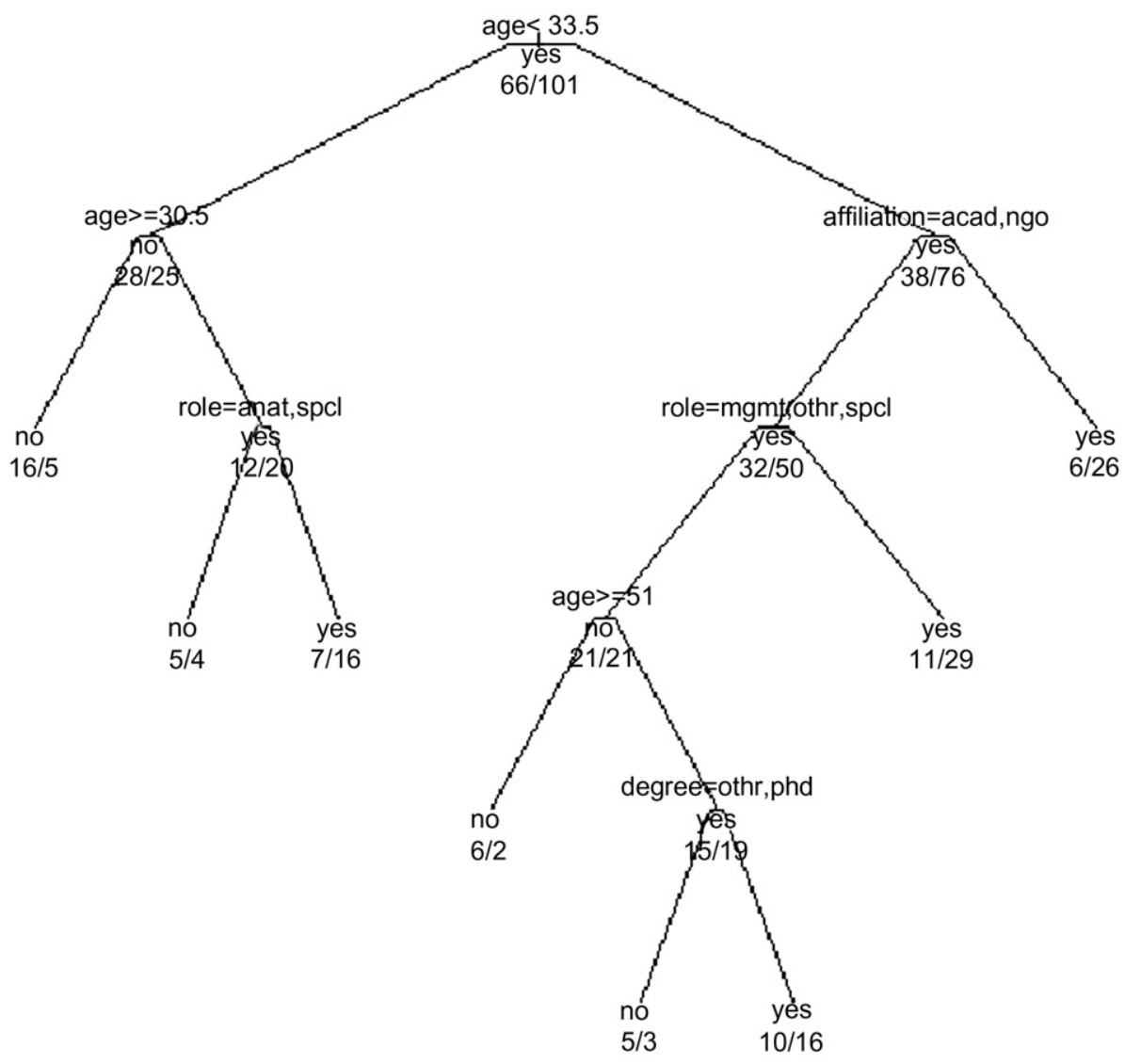

Fig. 2 - Classification tree model for question on "success" of Project Tiger. The text above each split shows the variable that is split and the condition for the left branch is stated. At the first node, age was the primary factor. Younger people (<33.5 years) were more likely to say "no". Among the older group, at the second node people affiliated with academic institutions and NGOs are less likely to say "yes". In the older group amateur naturalists and social scientists are more likely to say "yes", while natural scientists, conservation managers, and other professionals are more likely to say "no".

\subsection{Conservation initiatives and policies}

We examined attitudes towards four major conservation policies and initiatives in India. They are Project Tiger, Project Elephant, Forest Rights Act, and the Tiger Task Force Report. Project Tiger is one of India's most important conservation initiatives. The majority $(99 \%)$ of survey participants were aware of Project Tiger. Seventy-eight percent of respondents believed that the tiger is an effective umbrella species, and $60 \%$ of participants believed that Project Tiger was a complete "success". We modeled the effect of participant characteristics on "yes" or "no" responses to the success of this initiative. The resulting tree (Fig. 2) divides the participants into two groups determined primarily by age. Younger people (<33.5 years) are more likely to say "no" (53\%), and older people are more likely to say, "yes" (66\%, see Table 2). Most (89\%) participants were familiar with Project Elephant. Sixty-three percent of participants believed that the elephant is an effective umbrella species, and $51 \%$ of participants said considered Project Elephant a "success". The tree model for responses about this initiative identified age as the primary factor, with younger participants (<43.5 years) more likely to say "no" (54\%), and older people (>43.5 years) are more likely to say, "yes" $(60 \%$, see Table 2).

At the time of our survey in 2005, the Forest Rights Act was under debate in the Indian Parliament. Most participants (81\%) were familiar with the Act, and many felt that the bill required changes (63\%). The tree model identified academic degree as the primary factor influencing opinion about this Act. Those with doctoral degrees were more inclined to want the act changed (Table 2). Representative comments of participants' on the Forest Rights Act are in Table 4.

We also examined participants' attitudes towards the Tiger Task Force committee report. Among all participants, $38 \%$ thought the report was a step forward, $27 \%$ were unfamiliar with it, $20 \%$ thought it was no different, and $16 \%$ thought it was a step backward from previous reports. Tree models suggest that conservation involvement is the primary factor influencing opinion about this Task Force. Among those involved in conservation, $40 \%$ thought the report was a step forward from previous efforts of the Indian government (Table 2). A summary of participants' comments and observations on the Tiger Task Force Report are in Table 4. 


\section{Table 4 - Participants comments on conservation policies and initiatives}

Forest Rights Act

Positive comments

- Provides rights to forest dwellers, many of whom were marginalized and dispossessed historically (14)

- Could establish and revise reserve boundaries and forest cover. Identify land that is converted, and in use by people to settle property rights permanently (4)

Negative comments

- The Act will be misused, spells doom for protected areas, and wildlife. It disregards ecological consequences, will fragment reserves, increase encroachment, and humanwildlife conflicts. Ultimately, will decimate India's biodiversity (26)

- The Act is part of a political agenda. Pays lip service to both forest dwelling groups, and conservation without establishing criteria for serving either (14)

- Attempt to straightjacket and group people- cannot represent $500+$ forest dwellers with diverse historical, geographical, cultural, and socio-economic backgrounds. Disregards the changing needs of communities, their desire to integrate with society and live like everyone else. Relocate and resettle those that want to move, and provide them with appropriate resources (15)

- Contradicts provisions of the Wildlife Protection Act and requires further debate (11)
Tiger Task Force Report

Positive comments

- Recommendations are sound, but implementation is going to be a challenge (14)

- Pools together regional and local knowledge from across India, and encouraged inputs from the Indian conservationists (11)

- Information collected is exhaustive, and available to the public (7)

Negative comments

- Lacks depth, divisive, recommendations are contradictory and vague, and written by people with little scientific expertise (31)

- Anthropocentric and the focus is not the tiger, biased towards forests, and forest dwellers (17)

- Fails to address primary purpose of reviewing current tiger crisis, lacks long term vision, and fails to provide conservation road map for tiger conservation (13)

- Forest and wildlife departments are expected to do much (manage parks, enforce laws, oversee tourism, work with local communities, monitor wildlife, and conduct research).

- Does not hold them accountable for their failures and negligence particularly in places like Sariska (8)

- Disregards successful conservation efforts, ignores the role that NGOs play, and the need for collaboration with them (4)

\section{Conclusions}

Our study provides a number of insights about attitudes, and opinions of conservationists in India. Qualitative and quantitative responses of the participants demonstrated that many conservationists were aware of challenges, and problems facing Indian conservation. Although sample surveys provide a general and broad assessment of conservation attitudes, we recognize that additional insights may be gained from indepth interviews, and other qualitative research approaches to understand the plurality of factors influencing attitudes of conservation researchers and practitioners.

The use of tree models provided insights into participant characteristics that may influence attitudes of conservationists. The survey highlighted differences in awareness and interest levels among different respondent groups, as well as differences in conservation attitudes. For questions related to protected areas (use of force and people living in parks), affiliation was the primary response predictor. Academics were more likely to say "no" to the use of force in protecting reserves, and "yes" to people living inside protected areas. Those participants engaged in "hands-on" conservation (e.g., reserve managers, people in forest and wildlife departments) tended to be more skeptical that parks can achieve their conservation goals with people living in them. Perhaps these differences in factors reflect a more academic view of human behavior versus a more practical view informed by first hand experience with people and protected areas. With regard to Project Tiger and Elephant, older participants were more likely to think that these initiatives were successful.

This is perhaps because older participants have more experience with traditional conservation programs, while younger participants are more aware of newer research and monitoring tools (camera trapping versus pugmark census of tigers). Academic degree was the primary factor in predicting participants' opinion of the Forest Rights Act. Participants with doctoral degrees were more likely to think it needed revision. There is considerable controversy surrounding this Act, and its potential impacts on conservation in India. Perhaps those higher education levels are more aware of the issues surrounding the controversy. With respect to the Tiger Task Force Report, among those involved in conservation, some (40\%) thought it was a step forward. This may be because this high profile report has helped refocus national attention on conservation needs and challenges in India.

Our study has highlighted the differences and commonalities in opinion that exist among Indian conservationists (although our survey primarily focused on urban and semi-urban conservationists). India faces new conservation challenges with a rapidly growing economy, and the influence of globalization. Our participants suggested several ways to improve conservation research and management efforts. These included relocation of people (with compensation) from important reserves, stronger enforcement of existing wildlife laws, and greater involvement of local communities. Formation of committees to address crises (like the Tiger Task Force), or debates on laws (like the Forest Rights Act) require active participation of conservationists, and increasing awareness among the public. Understanding the views of different actors and agencies can lead to diminished conflict, 
more constructive debates, and provide improved opportunities for conservation.

Finally, debates on biological conservation reflect different viewpoints that are shaped by a variety of stakeholders' characteristics, particularly education levels, work environment, and age. This implies that consensus among conservationists about conservation strategies and policies will depend on forging alliances among those with quite different backgrounds. This research is a first step toward identifying sources of varying attitudes and opinions. Our research also suggests that the Indian conservation community may benefit from workshops and roundtable discussions comprised of conservationists with diverse backgrounds in the search for solutions for the country's increasingly complex challenges surrounding protected areas, nearby human communities, and tensions between conservation and development.

\section{Acknowledgements}

We thank the survey participants, G. Shahabuddin, K.U. Karanth, N.L. Cagle, M. Rangarajan, C. Clark, J.D. Nichols, P. M. Kumar, N.S. Kumar, and Centre for Wild life Studies (India). Duke University Institutional Review Board reviewed survey protocols. Karanth received support from a Duke University Graduate School International Travel Award 2005 and 2006.

\section{R E F E R E N C E S}

Bandara, R., Tisdell, C., 2003. Comparison of rural and urban attitudes to the conservation of Asian elephants in Sri Lanka: empirical evidence. Biological Conservation 110, 327-342.

Bhargav, P., 2007. Four hectares of forest: correcting history or destroying collective future. SANDEE Newsletter 14, 9-10.

Brieman, L., Friedman, J.H., Olshen, R.A., Stone, C.J., 1984. Classification and Regression Trees. Monterey, Wadsworth and Brooks/Cole.

Briggs, J., 2003. The biogeographic and tectonic history of India. Journal of Biogeography 30, 381-388.

Brook, A., Zint, M., Young, R.de., 2003. Landowners' response to an endangered species act listing and implications for encouraging conservation. Conservation Biology 17, 16381649.

Caro, T., Mulder, M.B., Moore, M., 2003. Effects of conservation education on reasons to conserve biological diversity. Biological Conservation 114, 143-152.

Champion, F.W., 1934. With a Camera in Tiger Land. Chatto \& Windus, London (p. 228).

Cirincione, C., Gurrieri, G.A., 1997. Research methodology: computer-intensive methods in the social sciences. Social Science Computer Review 15, 83-97.

Das, A., Krishnaswamy, J., Bawa, K.S., Kiran, M.C., Srinivas, V., Kumar, N.S., Karanth, K.U., 2006. Prioritization of conservation areas in the Western Ghats, India. Biological Conservation 133, $16-31$.

Forest Survey of India, 2000. State of the Forest Report. Forest Survey of India, Dehradun.

Gillingham, S., Lee, P., 1999. The impact of wildlife-related benefits on the conservation attitudes of local people around the Selous Game Reserve, Tanzania. Environmental Conservation 26, 218-228.
Goenka, D., 2005. A non-solution. Seminar 552, 35-36.

Hess, K.R., Abbruzzese, M.C., Lenzi, R., Raber, M.N., Abbruzzese, J.L., Abbruzzese, J.L., 1999. Classification and regression tree analysis of 1000 consecutive patients with unknown primary carcinoma. Clinical Cancer Research 5, 3403-3410.

Jayakrishnan, P.V., 2005. Is there a need for this bill? Seminar 552, 23-29.

Kaczensky, P., Blazic, M., Gossow, H., 2004. Public attitudes towards brown bears (Ursus arctos) in Slovenia. Biological Conservation 118, 661-674.

Kaltenborn, B.P., Bjerke, T., Nyahongo, J.W., Williams, D.R., 2006. Animal preferences and acceptability of wildlife management actions around Serengeti National Park. Biodiversity and Conservation 15, 4633-4649.

Karanth, K.K., 2007. Making resettlement work: the case of India's Bhadra Wildlife Sanctuary. Biological Conservation 139, 315324.

Karanth, K.K., Curran, L.M., Reuning-Scherer, J.D., 2006. Village size and forest disturbance in Bhadra Wildlife Sanctuary, Western Ghats, India. Biological Conservation 128, 147-157.

Karanth, K.U., 2003. Debating conservation as if reality matters. Conservation and Society 1, 65-68.

Karanth, K.U., Madhusudan, M.D., 2002. Mitigating humanwildlife conflicts in southern Asia. In: Terborgh, J., van Schaik, C., Davenport, L., Rao, M. (Eds.), Making Parks Work: Strategies for Preserving Tropical Nature. Island Press, Washington, DC, pp. 250-264.

Karanth, K.U., Bhargav, P., 2005. De-fragmenting nature. Seminar $552,59-62$.

Karanth, K.U., Karanth, K.K., 2007. Free to move: conservation and resettlement in the Western Ghats of Karnataka, India. In: Redford, K.H., Fearn, E. (Eds.), Protected Areas and Human Displacement: A Conservation Perspective, Working Paper 29. Wildlife Conservation Society, New York, pp. 48-59.

Kellert, S., 1991. Japanese perceptions of wildlife. Conservation Biology 5, 297-308.

Kleiven, J., Bjerke, T., Kaltenborn, B.P., 2004. Factors influencing the social acceptability of large carnivore behaviors. Biodiversity and Conservation 13, 1647-1658.

Kothari, A., 2005. Bungle in the jungle. Seminar 552, 63-79.

Kothari, A., Pathak, N., 2005. Forest and tribal rights. Frontline, 22.

Kramer, R.A., Sills, E.O., Pattanayak, S.K., 2008. National Parks as conservation and development projects: gauging local support. In: Karachepone, N. (Ed.), Conserving and Valuing Ecosystem Services and Biodiversity. Earthscan Press, London (forthcoming).

Krishnaswamy, M., 2005. One step forward two steps back. Economic and Political Weekly 47.

Madhusudan, M.D., 2005. Of rights and wrongs. Economic and Political Weekly 40, 4893-4895.

Madhusudan, M.D., Mishra, C., 2003. Why big, fierce animals are threatened: conserving large mammals in densely populated landscapes. In: Saberwal, V., Rangarajan, M. (Eds.), Battles Over Nature: Science and Politics of Conservation. Permanent Black, New Delhi, pp. 31-55.

Madhusudan, M.D., Shankar, K., Kumar, A., Mishra, C., Sinha, A., Datta, A., Rangarajan, M., Chellam, R., Shahabuddin, G., Sankaran, R., Singh, M., Ramakrishnan, U., Rajan, P.D., 2006. Science in the wilderness: the predicament of scientific research in India's wildlife research. Current Science 91, 10151019.

McFarlane, B.L., Stumpf-Allen, C.G., Watson, D.O., 2006. Public perceptions of natural disturbance in Canada's National Parks: The case of the mountain pine beetle (Dendroctonus ponderosae Hopkins). Biological Conservation 130, 340-348.

MOEF, 1999. National Policy and Macro level Action Strategy on Biodiversity New Delhi: Ministry of Environment and Forests, Government of India. 74pp. 
MOEF, 2000.Annual Report 2000-2001. New Delhi: Ministry of Environment and Forests, Government of India.

MOEF, 2003. The Wildlife Protection Act of 1972. As Amended up to 2003. Wildlife Trust of India. Nataraj Publishers, Dehra Dun.

MOEF, 2005. Joining the Dots, Report of the Tiger Task Force. New Delhi: Ministry of Environment and Forests, Government of India.

Mohanty, B., 2005. View from the field. Seminar 552, 30-34.

Prabhu, P., 2005. The right to live with dignity. Seminar 552, 14-19.

Pratt, D.G., Mac Millan, D.C., Gordon, I.J., 2004. Local community attitudes to wildlife utilization in changing the economic and social context of Mongolia. Biodiversity and Conservation 13, 591-613.

Ramnath, M., 2008. Surviving the Forest Rights Act between Scylla and Charybdis. Economic and Political Weekly 43, 37-42.

Rangarajan, M., 2001. India's Wildlife History. Permanent Black, New Delhi.

Rangarajan, M., 2005. Fire in the forest. Economic and Political Weekly 40, 4888-4890.

Rangarajan, M., 2006. Ideology, the environment, and policy: Indira Gandhi. India International Centre Quarterly 33, 50-64.

Rangarajan, M., 2007. Retreating elephant, vanishing tiger, the environmental legacies of India and China. In: Pande, I. (Ed.), India at Sixty. Harper Collins, Delhi, pp. 84-93.

Rangarajan, M., Shahabuddin, G., 2006. Displacement and relocation from protected areas: Towards a biological and historical synthesis. Conservation and Society 4, 359-378.

Rodgers, W.A., Panwar, H.S., 1988. In: Planning a Wildlife Protected Area Network in India, vol. 1. Wildlife Institute of India, Dehra Dun.

Saberwal, V., Rangarajan, M., Kothari, A., 2001. People, Parks and Wildlife. Towards Coexistence. Orient Longman Private Limited, New Delhi.

Saberwal, V., Rangarajan, M., 2003. Introduction. In: Saberwal, V., Rangarajan, M. (Eds.), Battles Over Nature: Science and Politics of Conservation. Permanent Black, New Delhi, pp. 1-30.
Sahgal, B., Raman, L., Basu, B., Shah, S., 2005. Citizens of the forest. Seminar 552, 44-49.

Sekhsaria, P., 2007. Conservation in India and the need to think beyond 'tiger vs tribal'. Biotropica 39, 575-577.

Shahabuddin, G., Rangarajan, M., 2007. Making Conservation Work: Securing biodiversity in this new century. Permanent Black, New Delhi (p. 312).

Sivaramakrishnan, K., 2003. Reflections on community involvement in conservation. In: Saberwal, V., Rangarajan, M. (Eds.), Battles Over Nature: Science and Politics of Conservation. Permanent Black, New Delhi, pp. 383-412.

Soto, B., Munthali, S.M., Breen, C., 2001. Perceptions of the forestry and wildlife policy by the local communities living in the Maputo Elephant Reserve, Mozambique. Biodiversity and Conservation 10, 1723-1738.

Stebbing, E.P., 1923. In: The Forests of India, vol. I. John Lane, London (p. 548).

Taverna, K., Urban, D.L., McDonald, R.I., 2004. Modeling landscape vegetation patterns in response to historic land use: a hypothesis-driven approach for the North Carolina Piedmont, USA. Landscape Ecology 20, 689-702.

UN, 2006. Human Development Report. Beyond Scarcity: Power, Poverty, and the Global Water Crisis. United Nations Development Programme. Palgrave Macmillan, New York.

Wezel van, M., Potharst, R., 2007. Improved customer choice predictions using ensemble methods. European Journal of Operational Research 181, 436-452.

Winter, S.J., Esler, K.J., Kidd, M., 2005. An index to measure the conservation attitudes of landowners towards Overberg Coastal Renosterveld, a critically endangered vegetation type in the Cape Floral Kingdom, South Africa. Biological Conservation 126, 283-394.

Qian, S.S., Anderson, C.W., 1999. Exploring factors controlling the variability of pesticide concentrations in the Williamette river basin using tree-based models. Environmental Science and Technology 33, 3332-3340. 